\title{
Estimation of Resilient Modulus of Unbound Granular Materials from Senegal (West Africa)
}

\author{
Adama Dione $^{1}$, Meissa Fall ${ }^{1}$, Yves Berthaud ${ }^{2}$, Makhaly Bâ ${ }^{1}$ \\ ${ }^{1}$ Laboratoire de Mécanique et Modélisation-UFR Sciences de l’ Ingénieur, Université de Thiès, Thiès, Sénégal \\ ${ }^{2}$ UFR Ingénierie, Université Paris VI-Pierre et Marie Curie, Paris, France \\ Email: adama.dione@univ-thies.sn
}

Received September 2, 2013; revised October 2, 2013; accepted October 9, 2013

Copyright (C) 2013 Adama Dione et al. This is an open access article distributed under the Creative Commons Attribution License, which permits unrestricted use, distribution, and reproduction in any medium, provided the original work is properly cited.

\begin{abstract}
The resilient modulus $\left(M_{r}\right)$ is an important parameter which describes the mechanical behavior of unbound granular materials. However, this parameter can be determined from physical properties. This paper presents the relationship between resilient modulus and physical properties of Quartzite from Bakel (GB), Basalt from Diack and Bargny and Bandia limestones. Simple and multiple regression method by stepwise are used to establish linear and nonlinear relations to predict the resilient modulus. The results showed no significant correlation for Basalt, a weak estimation of the modulus for GB and good prediction of resilient modulus for limestone. These results also showed that the model of Uzan is more suitable to predict the resilient modulus than NCHRP model and the resilient modulus is better predicted in nonlinear relationship.
\end{abstract}

Keywords: Resilient Modulus; Mechanical Behavior; Correlation; Physical Properties; Unbound Granular Materials

\section{Introduction}

The stiffness of granular materials was characterized in Senegal as in lots of other countries in the world, by Young's modulus $(E)$. This parameter supposed that the unbound granular materials were elastic linear. Recent studies have shown that the mechanical behavior of unbound granular materials is nonlinear elastoplastic (Huang, 2004) [1]. This behavior led scientists to define the resilient modulus, which replaces henceforth Young's modulus, in order to better characterize the real behavior of unbound materials. The resilient modulus is the primary input on materials properties in the NCHRP 1-37 (2004) guide. It is very important to calculate the stress, strains and deflections of pavement under wheel load. However, the determination of resilient modulus is time consuming, requires sophisticated equipment which is costly as well as skilled personnel for laboratory. It is so important to predict resilient modulus in order to reduce cost and time in road project. In addition, the resilient modulus is influenced by many factors, the most important of them are stress level and material properties (Lekarp et al., 2000 [2]). This article presents the estimation of resilient modulus of unbound materials from Senegal based on physical properties, since the physical properties are easy to obtain in laboratory and are not expen- sive.

\section{Background}

Since 1960, numerous research efforts have been developed to characterize the resilient behavior of granular materials (Lekarp et al., 2000 [2]). In Senegal, the investigation on mechanical behavior of unbound materials goes up since twenty years. Fall (1993) [3] has announced for the first time, the importance of adequacy input for pavement design. He underlines the first advanced mechanical properties of lateritic soil from Senegal. Ba (2012) [4] also studied the mechanical behavior under cyclic wheel load of granular materials (Diack Basalt, Quartzite from Bakel and limestones from Bargny and Bandia) and defined resilient modulus of these materials. This concept of resilient is introduced by Seed et al. in 1960 (Angelone and Martinez, 2000 [5]) and can be defined as the ratio of the repeated axial deviatory stress to the recoverable axial strain (Figure 1).

$$
M_{r}=\frac{\sigma_{1}-\sigma_{3}}{\varepsilon_{a}}=\frac{\sigma_{d}}{\varepsilon_{a}}
$$

$M_{r}$ : resilient modulus $(\mathrm{kPa}), \sigma_{1}$ : major stress $(\mathrm{kPa}), \sigma_{3}$ : minor stress $(\mathrm{kPa}), \sigma_{d}$ : deviatoric stress $(\mathrm{kPa}), \varepsilon_{a}$ : recoverable strain. 


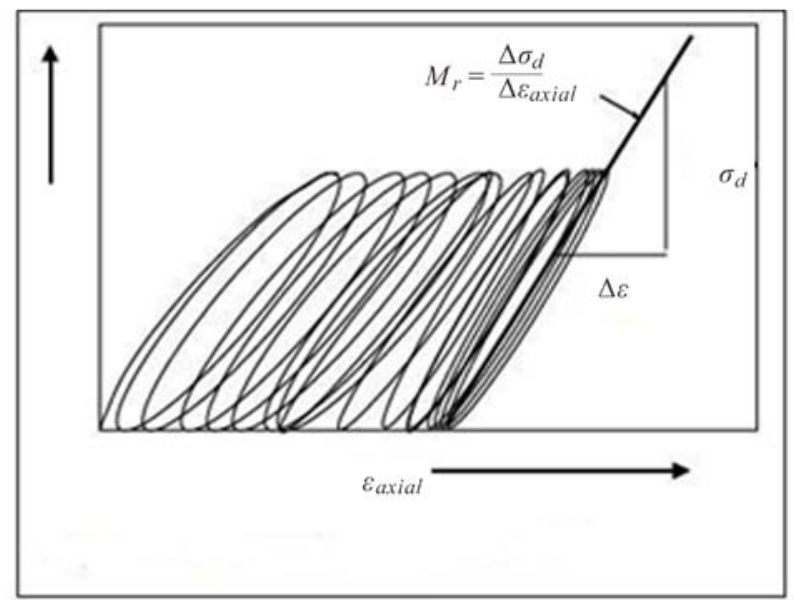

Figure 1. Definition of resilient modulus (Hopkins et al., 2004 [6]).

However, since the laboratory determination of resilient modulus is complex, costly and time consuming, resilient modulus can be estimated based on correlation with physical properties. In Senegal no studies for estimating resilient modulus were performed. But in the world there are many studies for predicting resilient modulus from physical proprieties.

Jones and Witczak (1977) [7] developed two correlation equations for A-7-6 subgrade soil in California, combining the water content and the degree of saturation. The results show a coefficient of 0.96 for compacted soil and 0.45 for undisturbed soil. Carmichael and Stuart (1985) [8] developed two relations result from tests conducted on 250 soils. Yau and Von Quintus (2002) [9] proposed an equation for predicting resilient modulus. They found that the equation did not fit all situations. George (2004) [10] found linear and nonlinear relationships for estimating resilient modulus for fine and coarse grained soils from physical properties. Kim et al. (2007) [11] established relationships to estimate models parameters of resilient modulus. Van Aswegen and Steyn (2013) [12] also study the statistical modeling of the resilient behavior of unbound granular material of South Africa soils. These studies are very important for estimating resilient modulus of unbound granular materials.

\section{Characteristics of Materials and Testing Procedure}

\subsection{Characteristics of Materials}

The materials used in this study are unbound aggregates coming from various geological formations of Senegal. They are amongst others like the Bakel Quartzite, the Diack Basalt and Bargny and Bandia Limestones (Figure 2). These materials were used in base course as alternative materials to the lateritic soils.

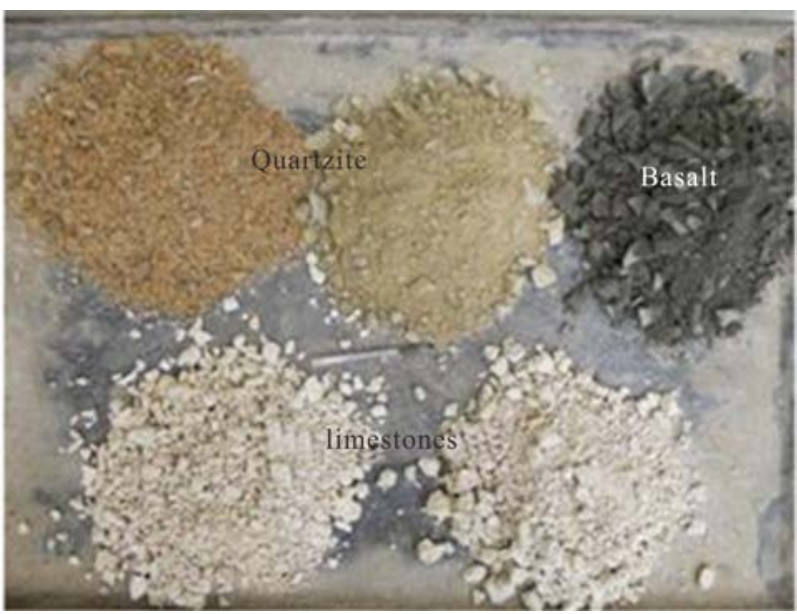

Figure 2. Various materials of the study (Ba, 2012) [4].

The database is collected from Ba (2012) [4] in order to obtain material characteristics. The sizes used are $0 / 20$ and 0/31.5 for Bakel Quartzite and limestones and only 0/31.5 for Diack Basalt. Grain size distributions (Figure 3) and conditions of compaction for the materials are performed respectively according to standard ASTM C136-06 and ASTM D1557-09.

\subsection{Testing Procedure}

Specimens were subjected to the resilient modulus test procedure. A MTS closed-loop servo-electro-hydraulic testing system was used to apply the cyclic loading in a haversine waveform, with 0.1 second of loading duration and 0.9 second of rest period. Displacements were measured internally using "Linear Variable Displacement Transducer" ("LVDT") mounted around the specimen inside the cell. The specimens have been tested using the NCHRP Protocol 1-28. Each specimen was conditioned with $103.5 \mathrm{kPa}$ confining pressure, and 1000 cycles of $207 \mathrm{kPa}$ deviator stress. The cycles are repeated 100 times for 30 loading sequences with different combinations of confining pressures and deviator stresses. The last five cycles of each sequence are used to calculate the resilient modulus (Ba, 2011) [13].

\section{Statistical Analysis}

The resilient modulus test results and physical properties of materials collected from Ba (2012) [4] were analyzed using statistica software. The data base is not large, so it is not adequate to perform suitable statistical analysis. But it is important to define basic knowledge for correlating resilient modulus of unbound granular materials of Senegal.

\subsection{Description of Variables}

The variables used in this analysis are resilient modulus 


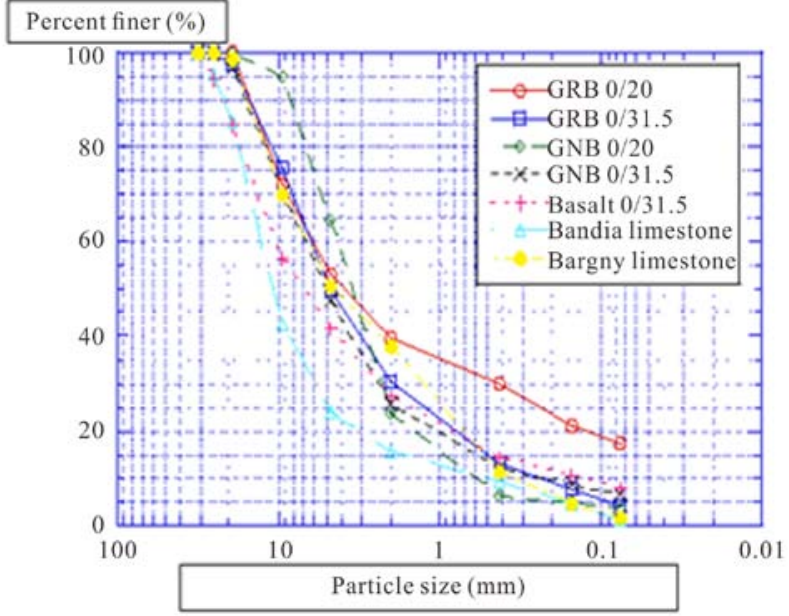

Figure 3. Particles size distribution for the 4 materials (Ba, 2012) [4].

which is the dependent variable and physical properties of unbound granular materials represent the independent variables. There are water content $(\mathrm{W})$, optimum water content $\left(\mathrm{W}_{\mathrm{opt}}\right)$, dry density $\left(\gamma_{\mathrm{d}}\right)$, maximum dry density $\left(\gamma_{\mathrm{dmax}}\right)$, the percentage of fine particles (\% fine), the percent passing on sieve $2 \mathrm{~mm}\left(\mathrm{P}_{2}\right)$, the maximum size of particle $\left(D_{\max }\right)$, the coefficient of uniformity $(\mathrm{Cu})$ and the coefficient of curvature (Cc). The resilient modulus was calculated using Uzan and NCHRP models, because they are more suitable to predict the resilient modulus (Ba, 2011) [13]. They are determined from states of stresses usually found in base course defined by NCHRP (2004) [14]. There is summary resilient modulus which is used to perform correlations. The following equations show the models as well as the states of stresses used.

$$
\begin{aligned}
& M_{r}=k_{1} P a\left(\frac{\theta}{P a}\right)^{k_{2}}\left(\frac{\sigma_{d}}{P a}\right)^{k_{3}} \text { Uzan model } \\
& M_{r}=k_{1} P a\left(\frac{\theta}{P a}\right)^{k_{2}}\left(\frac{\tau_{o c t}}{P a}+1\right)^{k_{3}} \text { NCHRP model }
\end{aligned}
$$

$M_{r}$ : resilient modulus $(\mathrm{MPa}), \theta$ : bulk stress $=208 \mathrm{kPa}$, $\tau_{\text {oct }}$ : octaedral shear stess $=48.55 \mathrm{kPa}, \mathrm{Pa}$ : atmospheric pressure $=101.3 \mathrm{kPa}, \sigma_{d}$ : deviatoric stress $103 \mathrm{kPa}, k_{i}$ : model parameters $(\mathrm{kPa})$.

\subsection{Relationships between Variables}

After describing the variables, we will carry out a Principal Component Analysis (PCA) to look for relationships between variables. This analysis allowed the detection of the relationships between variables and helped to choose the best type of regression, Figures 4-6 represent the PCA performed with GB, Diack Basalt and limestones. The result shows for GB (Figure 4) that the resilient modulus is explained at $67.64 \%$, and is posi-

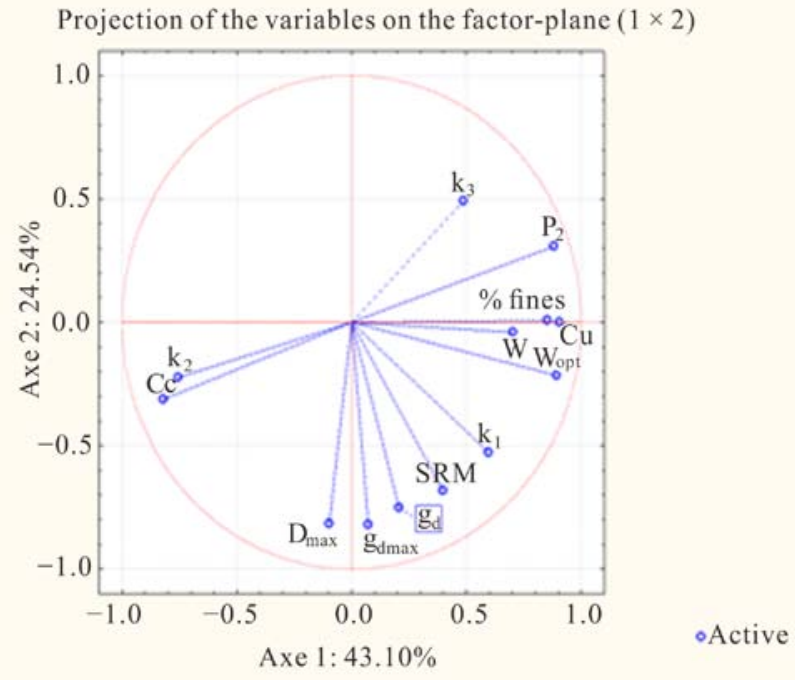

Figure 4. Principal Component Analysis performed on GB.

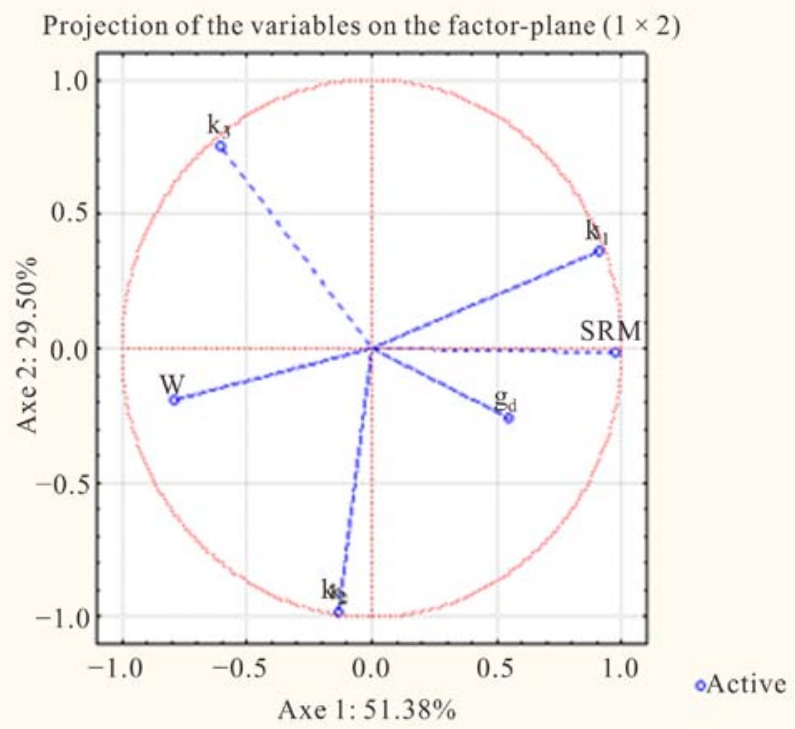

Figure 5. Principal Component Analysis performed on the basalt.

tively dependent on $\gamma_{\mathrm{d}}, \gamma_{\mathrm{dmax}}$ and $\mathrm{D}_{\max }$ and negatively dependent on $\mathrm{W}_{\mathrm{opt}}, \mathrm{P}_{2} \mathrm{~W}$ and \% fines. For the Diack Basalt (Figure 5), the resilient modulus is positively dependent on $\gamma_{\mathrm{d}}$ and negatively dependent on $\mathrm{W}$, it is explained at $80.88 \%$. For limestones (Figure 6) the resilient modulus is explained at $81.21 \%$ and is positively dependent on $\gamma_{\mathrm{d}}$ and negatively on W. These PCA do not justify a real connection with resilient modulus. They give just an overall vision on the touchiness of possible relations with the modulus.

There are also other methods such as the examination of the matrix of correlation and the stepwise method which guided the selection of the best variables in the models. 


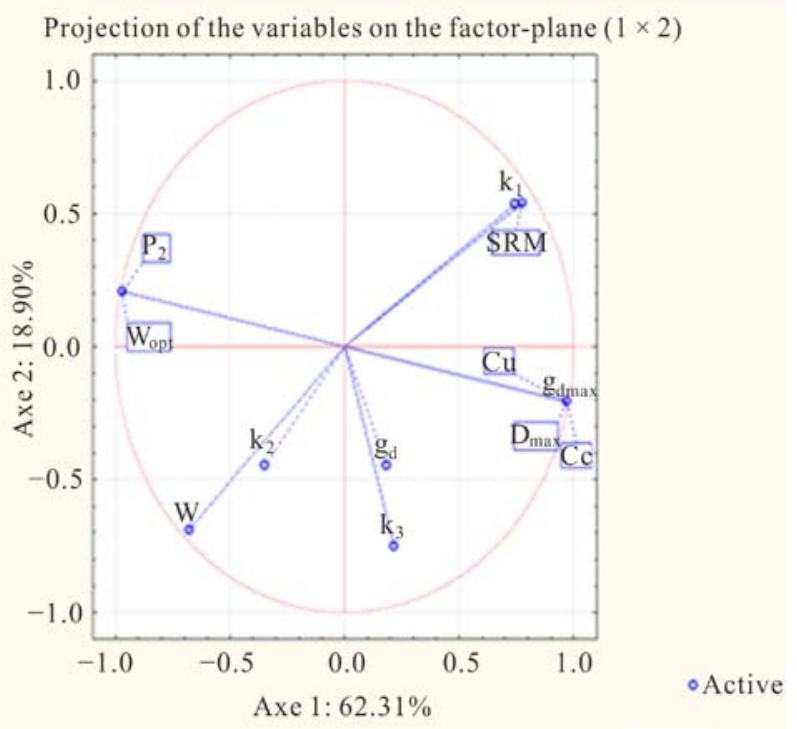

Figure 6. Principal Component Analysis performed on limestones.

\subsection{Correlation Analysis}

In this analysis, regression method by stepwise is used. It is based on the coefficient of determination $\mathrm{R}^{2}$ and the tests of Student and Fischer. Only the variables most correlated and satisfactory with tests are selected in the model. These tests are associated at the p-level, and all variables inferior at threshold (0.05) are significant. However, linear and nonlinear relationships are determined for all materials. Indeed, multicolinearity test is performed between independent variables, in order to prevent bias relations. For the majority of our relations, the following general equation is used.

$$
Y=\beta_{0}+\beta_{1} X_{1}+\beta_{2} X_{2}+\cdots \beta_{p} X_{p}+\varepsilon
$$

$Y$ : dependent variable (resilient modulus), $\beta_{0}$ : intercept, $\beta_{i}$ : model parameters, $X_{i}$ : independent variables (physical properties), $\varepsilon$ : error.

The results show no correlation for Diack Basalt because there is a lack of data. They also show that the resilient modulus is weakly explained for GB with $R^{2}$ of 0.34 and 0.32 for Uzan and NCHRP (2004) models. For limestones, there are a $\mathrm{R}^{2}$ of 0.96 for Uzan model and a $R^{2}$ of 0.94 for NCHRP model. The summary of the relations established in linear regression according to the models of Uzan and NCHRP (2004) gave the following equations:

\section{- GB for UZAN model}

$$
\begin{aligned}
& S R M=-307.840+21.622 \times\left(\gamma_{d}\right) \\
& R^{2}=0.34
\end{aligned}
$$

\section{- GB for NCHRP model}

$$
\begin{aligned}
& S R M=-302.578+21.556 \times\left(\gamma_{d}\right) \\
& R^{2}=0.32
\end{aligned}
$$

\section{- Limestone for UZAN model}

$$
\begin{aligned}
& S R M=-1384.14-41.50 \times(W)+96.34 \times\left(\gamma_{d}\right) \\
& R^{2}=0.96
\end{aligned}
$$

\section{- Limestone for NCHRP model}

$$
\begin{aligned}
& S R M=-1337.91-44.50 \times(W)+95.81 \times\left(\gamma_{d}\right) \\
& R^{2}=0.94
\end{aligned}
$$

SRM: Summury Resilient Modulus (MPa), W: water content (\%), $\gamma_{d}$ : dry density $\left(\mathrm{kN} / \mathrm{m}^{3}\right)$.

Figures 7-11 show the scatter between measured and predicted resilient modulus for several materials in linear models. They show a scatter plot widely dispersed for Basalt, moderately dispersed for GB and a scatter plot showing a good correlation for limestones.

There are also nonlinear relationships developed in this paper. They showed as in linear relations that the resilient is weakly explained for GB with $R^{2}$ of 0.38 and

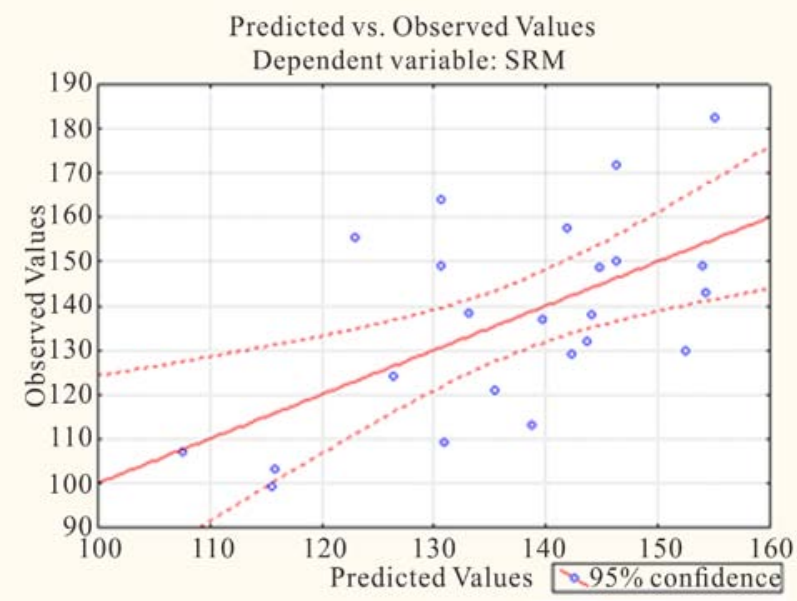

Figure 7. Relation between actual and predicted resilient modulus for GB of the model of Uzan in linear model.

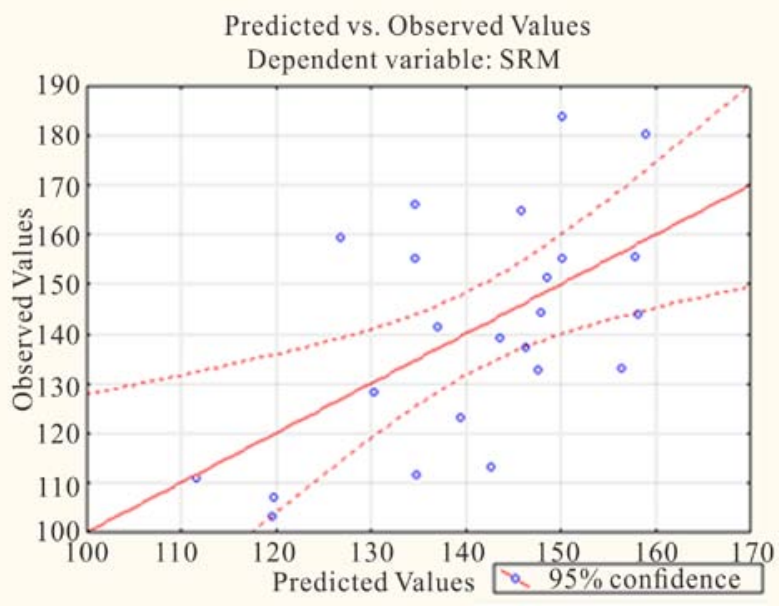

Figure 8. Relation between actual and predicted resilient modulus for GB of the model of NCHRP in linear model. 


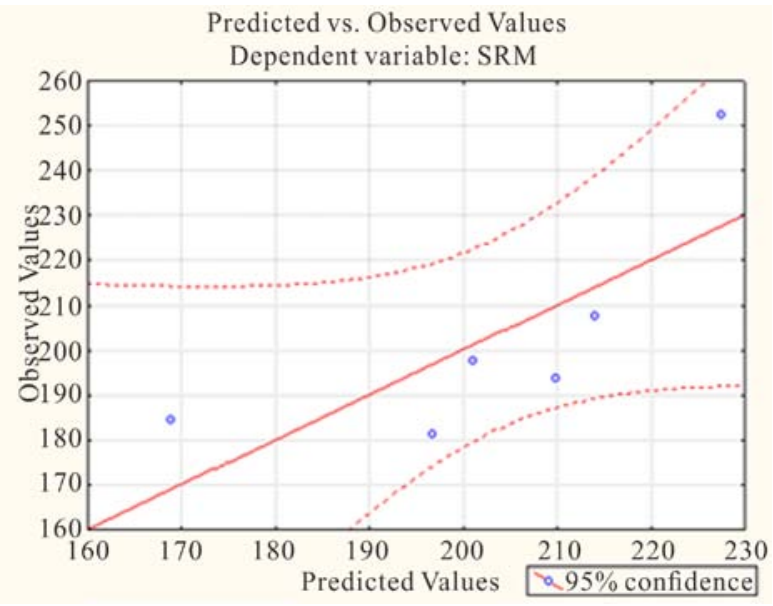

Figure 9. Relation between actual and predicted resilient modulus for basalt of the model in linear model.

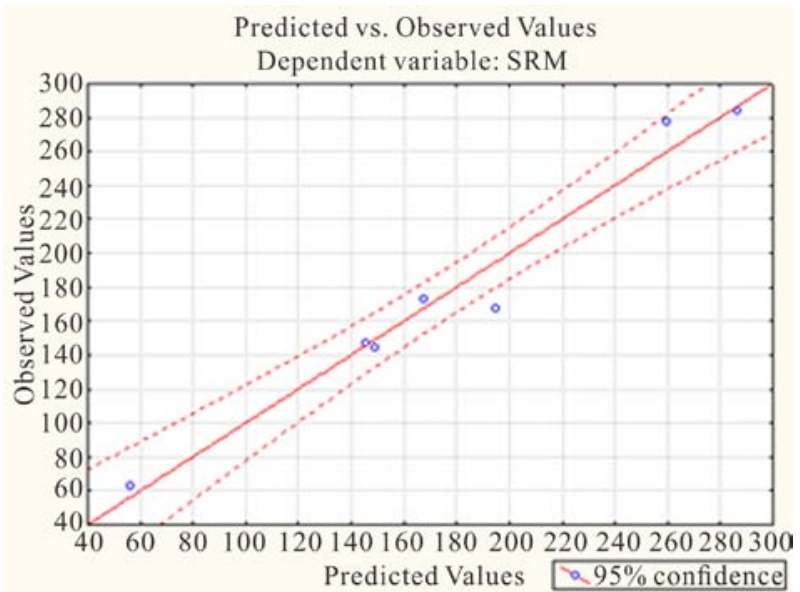

Figure 10. Relation between actual and predicted resilient modulus for limestones of the model of Uzan in linear model.

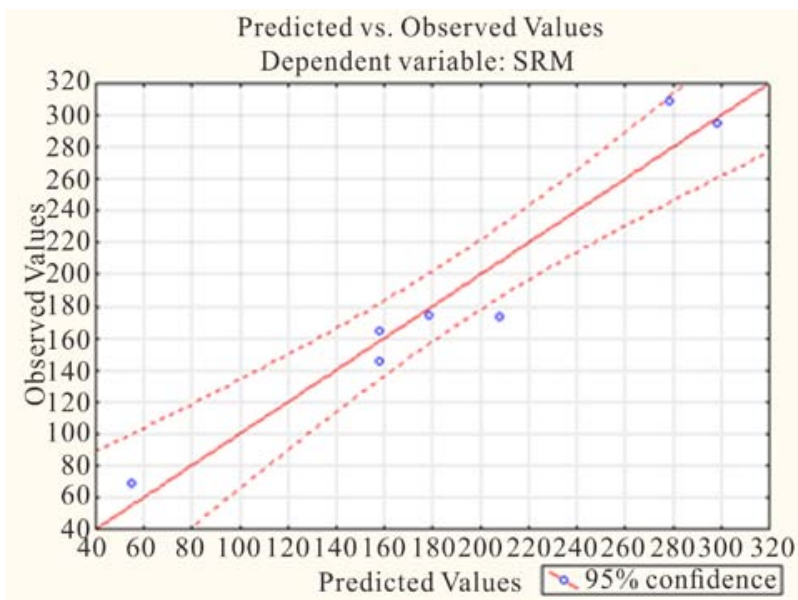

Figure 11. Relation between actual and predicted resilient modulus for limestones of the model of NCHRP in linear model.
0.34 for Uzan and NCHRP (2004) models. For limestones, there are a $\mathrm{R}^{2}$ of 0.98 for Uzan model and a $\mathrm{R}^{2}$ of 0.98 for NCHRP model. The result also showed that the $\mathrm{R}^{2}$ is increasing in nonlinear models. Indeed; the used of nonlinear models are the best for predicting resilient modulus. The models in nonlinear relationships are represented by the following equations:

\section{- GB for UZAN model}

$$
\begin{aligned}
& \log (S R M)=3.5772-\frac{29.4738}{\gamma_{d}} \\
& R^{2}=0.38
\end{aligned}
$$

\section{- GB for NCHRP model}

$$
\begin{aligned}
& \log (S R M)=3.6107-\frac{30.4144}{\gamma_{d}} \\
& R^{2}=0.36
\end{aligned}
$$

\section{- Limestone for UZAN model}

$$
\begin{aligned}
& \log (S R M)=6.5578-0.0064 \times(W)^{2}-\frac{76.8718}{\gamma_{d}} \\
& R^{2}=0.98
\end{aligned}
$$

\section{- Limestone for NCHRP model}

$$
\begin{aligned}
& \log (S R M)=1.4702-0.1178 \times(W)+0.0044 \times\left(\gamma_{d}\right)^{2} \\
& R^{2}=0.98
\end{aligned}
$$

SRM: Summary Resilient Modulus (MPa), W: water content (\%), $\gamma_{d}$ : dry density $\left(\mathrm{kN} / \mathrm{m}^{3}\right)$.

In nonlinear model, Figures 12 and $\mathbf{1 3}$ show a bad distribution of points resulting from low correlation with GB. However, a good estimation was noted for limestones Figures 14 and 15 show a good distribution of points resulting from good estimation of resilient modulus of limestones from physical properties.

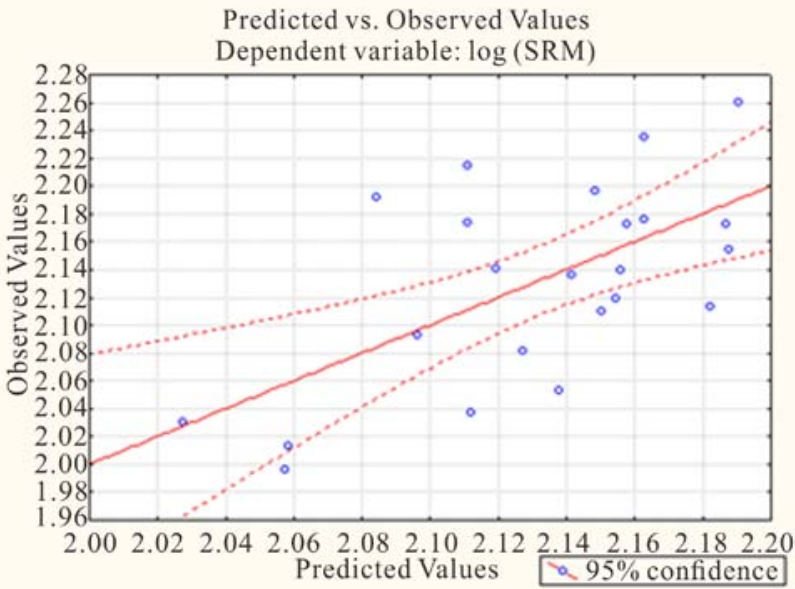

Figure 12. Relation between actual and predicted resilient modulus for GB of the model of Uzan in nonlinear model. 


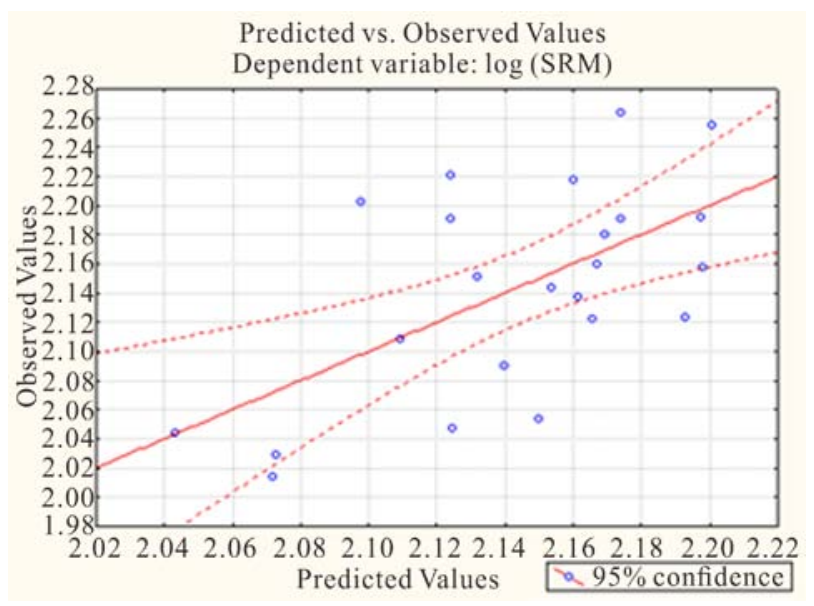

Figure 13. Relation between actual and predicted resilient modulus for GB of the model of NCHRP in nonlinear model.

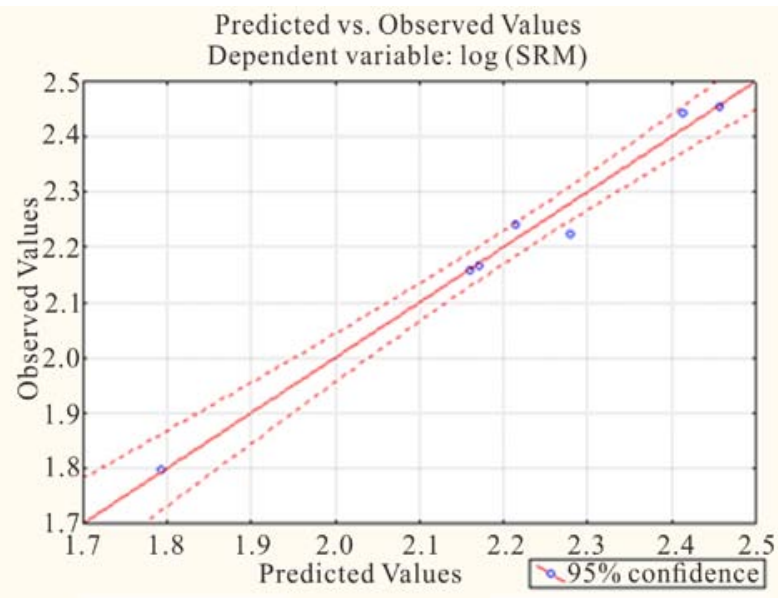

Figure 14. Relation between actual and predicted resilient modulus for limestones of the model of Uzan in nonlinear model.

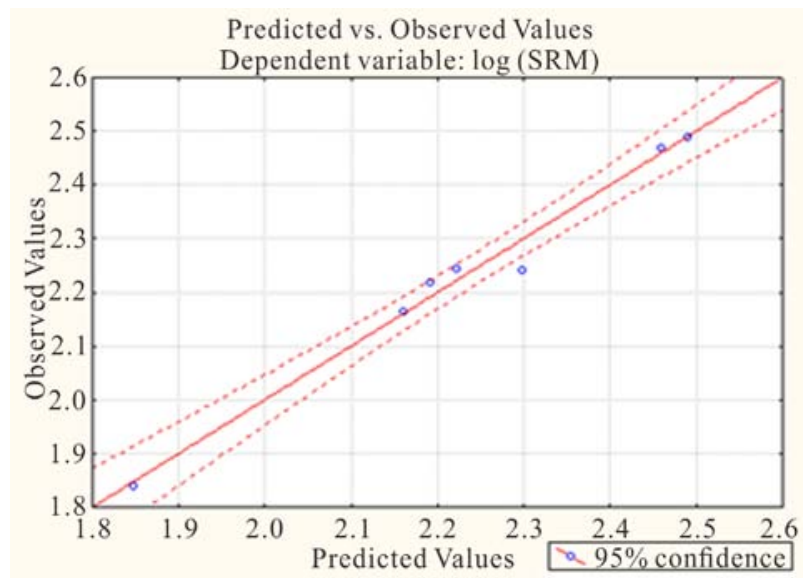

Figure 15. Relation between actual and predicted resilient modulus for limestones of the model of NCHRP in nonlinear model.

\section{Conclusion}

The estimation of the resilient modulus of GNT from Senegal, shows that the Uzan model is more suitable for predicting the materials. However, there is no correlation for the basalt due to the deficiency of significant variables, a weak correlation for GB and a good relationship for limestones which have a strong affinity with water. The results also show that the resilient is better predicted in nonlinear models. This study is important to get a way to estimate suitability of the resilient modulus, but the relations cannot be used for all situations, because of the small size of data base.

\section{Acknowledgements}

We would like to acknowledge Dr. Makhaly Ba to have placed at our disposal the unit of its experimental results, which were useful for this article. We also thank the French cooperation for the granting for a research grant in Paris VI.

\section{REFERENCES}

[1] Y. Huang, "Pavement Analysis and Design,” 2nd Edition, Prentice-Hall, Inc., Upper Saddle River, New Jersey, 2004.

[2] F. Lekarp, U. Isacsson and A. Dawson, "State of the Art. I: Resilient Response of Unbound Aggregates,” Journal of Transportation Engineering, Vol. 126, No. 1, 2000, pp. 66-75.

[3] M. Fall, "Identification et Caractérisation Mécanique de Graveleux Latéritiques du Sénégal: Application au Domaine Routier,” Thèse de Doctorat INPL, 1993, 240 p.

[4] M. Ba, "Comportement Mécanique sous Sollicitations Cycliques de Granulats Quartzitiques de Backel-Comparaison avec des Matériaux de Référence du Sénégal et d'Amérique (USA): Application au Dimensionnement Mécanistique des Chaussées Souples,” Thèse de Doctorat Université Cheikh Anta Diop de Dakar, 2012, p. 239.

[5] S. Angelone and F. Martinez, "Analysis of Non-Linear Models Describing the Resilient Behavior for Soils and Unbound Materials,” 2000.

[6] T. C. Hopkins, T. L. Beckham and C. Sun, "Resilient Modulus of Compacted Crushed Stone Aggregate Bases,” Research Report KTC-05-27/SPR-229-01-1F, Kentucky Transportation Center, College of Engineering, University of Kentucky, 2007, p. 89.

[7] M. P. Jones and M. W. Witczak, "Subgrade Modulus on the San Diego Test Road,” Transportation Research Record 641, TBR, National Research Council, Washington, 1977, pp. 1-6.

[8] R. F. Carmichael and E. Stuart, "Predicting Resilient Modulus: A Study to Determine the Mechanical Properties of Subgrade Soils,” Transportation Research Record 1043, TBR, National Research Council, Washington, D.C., pp. 20-28. 
[9] A. Yau and V. Quintus, "Study of LTPP Laboratory Resilient Modulus Test and Response Characteristics," Final Report, US Department of Transportation Federal Highway Administration Research Development and Technology, 2002.

[10] K. P. George, "Prediction of Resilient Modulus from Soil Index Properties,” Final report, Mississippi Department of Transportation, Research Division, Jackson, 2004, p. 71.

[11] M. Kim, “The Three-Dimensional Finite Element Analysis of Flexible Pavements Considering Nonlinear Pavement Foundation Behavior,” Ph.D. Thesis, University of
Illinois, Urbana Illinois, 2007.

[12] E. A. Van and W. J. V. Steyn, "Statistical Modeling of the Resilient Behavior of Unbound Granular Material," Vol. XXI, 2013, pp. 9-16.

[13] M. Ba, M. Fall, F. Samb, D. Sarr and M. Ndiaye, "Resilient Modulus of Unbound Aggregate Base Courses from Senegal (West Africa),” 2011, 6 p.

[14] NCHRP, "Laboratory Determination of Resilient Modulus for flexible Pavement Design,” National Cooperative Highway Research Program, Transportation Research Board of National Academies, Washington, 2004. 